\title{
PROPOSICCÃO, FRASE, PERÍODO: UMA QUESTÃO EPISTEMOLÓGICA OU HERMENÊUTICA?
}

\author{
PROPOSITION, PHRASE, PERIOD: AN EPISTEMOLOGICAL \\ OR HERMENEUTIC QUESTION?
}

Silvana SILVA ${ }^{1}$

Resumo: O objetivo deste trabalho é criar condições epistemológicas para avançar a discussão sobre a querela das unidades linguísticas ditas "intermediárias" entre o signo e o texto. Essa querela atravessa a tradição gramatical e por meio dela surgiram inúmeras classificações: frase, proposição, período, parágrafo, sintagma, cláusula, unidades estas com definições e entendimentos diferentes por vários autores. Este trabalho centraliza sua atenção na polêmica instaurada por Bronckart (2017) sobre tais unidades, em especial sua leitura crítica de Berrendoner e Béguelin (1989). Para resolver essa polêmica, que redundou em um dilema epistemológico, optamos por uma abordagem hermenêutica, tal como elaborada por Fenoglio (2019), uma das especialistas na obra do linguista Émile Benveniste. A conclusão geral é que nem Bronckart (2017) tampouco Berrendoner e Béguelin (1989) trazem solução para o problema das unidades da língua, posto que a frase introduz na língua uma epistemologia do imprevisível linguageiro.

Palavras-chave: Unidades da língua. Níveis de análise linguística. Bronckart. Adam. Benveniste.

\begin{abstract}
The aim of this paper is to create epistemological conditions to advance the discussion about the quarrel of the so-called 'intermediate' linguistic units between the sign and the text. This quarrel crosses the grammatical tradition and through it arose innumerable classifications: phrase, proposition, period, paragraph, syntagma, clause, units with different definitions and understandings by various authors. This paper focuses its attention on the controversy introduced by Bronckart (2017) about such units, especially his critical reading by Berrendoner and Béguelin (1989). To solve this controversy, which resulted in an epistemological dilemma, we opted for a hermeneutic approach, as elaborated by Fenoglio (2019), one of the specialists in the work of linguist Émile Benveniste. The general conclusion is that neither Bronckart (2017) nor Berrendoner and Béguelin bring a solution to the problem of language units since the phrase introduces into the language an epistemology of the unpredictability.
\end{abstract}

Keywords: Units of language. Levels of linguistic analysis. Bronckart. Adam. Benveniste. 
“O que a gente tem que aprender é, a cada instante, afirmar-se com uma linhazinha para saber passar no fio da agulha que cada momento exige."

(João Guimarães Rosa)

\section{Introdução}

Este texto surge da necessidade de debater um posicionamento assumido por Bronckart (2017) sobre as unidades da língua e sua própria natureza no artigo intitulado "Mônada, frase, proposição? Desafios de um debate conceitual". O próprio texto de Bronckart não é a conceitualização das unidades da língua e sim apenas uma discussão da proposta de Berrendoner e Béguelin (1989). Apesar da aparente simplicidade do texto para uma discussão antiga, Bronckart (2017) provoca, a nosso ver, uma discussão epistemológica importante para a linguística, em especial para a área dos estudos do discurso, que, muitas vezes, se deu por satisfeita com a noção de enunciado ou ainda com a noção de gênero, sem entrar na extensa e heterogênea seara da discussão sobre frase, período, proposição, sequência, gênero. Bronckart (2017) problematiza não somente o fato de os linguistas ainda não terem dado uma resposta definitiva à questão, mas também indiretamente sobre a natureza da linguagem, ao criticar a distinção benvenisteana de língua e discurso. Além disso, toca no método de depreensão das unidades da língua (descendente ou ascendente), apresentando seu posicionamento da questão, que se alinha ao pensamento de Bakhtin.

Em síntese, o artigo de Bronckart (2017) toca em três questões importantes para a linguística: 1) a natureza da linguagem e a sua capacidade de segmentação em unidades; 2) a necessidade de o linguista determinar quais as unidades da língua na passagem da sintaxe ao texto; 3) a discussão do método de observação e de segmentação das unidades da língua. Essas três questões se entrelaçam no texto em comento.

No entanto, para fins de discussão, este texto será ordenado da seguinte forma: em primeiro lugar, apresentaremos os principais pontos de "debate" de Bronckart (2017) tanto com Berrendoner e Béguelin (1989) quanto com Benveniste. Em seguida, apresentaremos a nossa leitura do texto de Berrendoner e Béguelin (1989). Depois, apresentaremos nosso posicionamento sobre a natureza da linguagem, a discussão do método de observação das unidades da língua e a sua segmentação. Para isto, traremos para o "debate" o teórico do texto Jean Michel Adam (2019), uma vez que o primeiro nos oferece pistas para constituir uma proposta à primeira e à segunda questões, bem como Fenoglio (2019), já que ela traz uma leitura muito acurada da obra de Émile Benveniste, nos ajudando a responder assim 
à terceira questão. Quanto à segunda questão, isto é, saber quais são, afinal, as unidades da língua, na passagem da sintaxe ao texto, acreditamos que, somente com o debate cuidadoso de algumas propostas de classificação, poderemos vislumbrar uma resposta a essa questão que a Saussure deixou intrigado.

\section{O debate Bronckart (2017) e Berrendoner e Béguelin (1989)}

Bronckart (2017) inicia o texto retomando a contribuição e o esforço de Berrendoner e Béguelin (1989). Na citação abaixo, já podemos entrever que a proposta dos autores enfrentará críticas de Bronckart:

Preocupados em se liberar das pseudoevidências oriundas da tradição gramatical, tentaram estabelecer as bases de uma abordagem racional e científica das relações entre morfemas, lexemas sintagmas; o que o conduziu a evidenciar os múltiplos problemas de definição e delimitação da noção de frase, e recomendar o abandono dessa noção e introduzir as noções de mônada e período, a primeira tendo o estatuto de entidade máxima da sintaxe de recção; a segunda de entidade de nível superior que é objeto de uma pragma-sintaxe de ordem discursiva. (BRONCKART, 2017, p. 51-52).

Bronckart (2017) inicia a apresentação da crítica de Berrendoner e Béguelin (1989) à noção de frase a partir da imediata relação problemática estabelecida entre frase e frase gráfica. A identidade de frase com frase gráfica gera dois tipos de problemas: 1) heterogeneidade de critérios de identificação da frase (semântico, prosódico, tipográfico), gerando confusão em função de todos os critérios não se recobrirem mutuamente; 2 ) a unidade maximal frase não constitui o limite da combinatória sintática, não é sua extensão máxima (BRONCKART, 2017).

Considerando esses problemas, Berrendoner e Béguelin (1989, p. 54) propõem uma gramática intuitiva, isto é, uma forma de conhecimento intuitivo e espontâneo dos falantes, "sem a descontinuidade do morfema ao enunciado.". Para ilustrar melhor o que seria essa gramática intuitiva, Bronckart (2017, p. 54) traz uma citação de Berrendoner e Béguelin (1989), na qual se lê que "a articulação 'natural' [...] desempenha uma função derivada de uma natureza quase epistemológica" ${ }^{2}$. Na página 57 , Bronckart atribui a distinção elaborada por Berrendoner e Béguelin entre mônada, unidade máximal da

\footnotetext{
2 Em breve, discutiremos esse termo quase epistemológico, pois ele desempenha um papel estratégico na
} crítica de Bronckart (2017) aos autores. 
- | Proposição, frase, período: uma questão epistemológica ou hermenêutica?

sintaxe de recção, e período (1989) à unidade supraordenada de realização dos atos enunciativos, à clássica divisão "língua como sistema de signos" e "língua como unidade semântica", proposta por Benveniste em "Níveis de análise linguística" (PLG I).

Na seção Questões e Problemas, Bronckart (2017) levanta uma série de problemas que, a seu ver, apresenta a classificação dos autores, quais sejam: 1) as várias acepções da noção defrase: apesar de denunciarem a heterogeneidade de critérios para definir a frase, os autores recorrem a, pelo menos, duas grandes acepções (frase sintática e frase semântica); 2) definição da metodologia de análise, ascendente ou descendente: Bronckart mostra que os autores adotam uma perspectiva ascendente, que coloca o texto como "horizonte", fato que contraria os atuais estudos pragmáticos; alia-se por sua vez a Voloshinov, que postula método descendente de análise das unidades da língua, pois "as diversas redes de estruturação textual exercem uma influência evidente sobre o aspecto possível das mônadas e sobre seus modos de encadeamento" (BRONCKART, 2017, p. 60). 3) a matriz epistemológica: Bronckart discorda de Benveniste nos seguintes termos: "Se os fenômenos visados apresentam evidentemente diferenças que os autores têm perfeitamente razão em conceitualizar, enviá-los a subdomínios "irredutíveis" nos parece constituir uma excessiva extrapolação epistemológica. Só existe uma linguagem humana, integralmente constituída de signos e cuja propriedade maior e definidora é servir simultaneamente à representação e à comunicação." (BRONCKART, 2017, p. 61, grifos nossos); 4) a universalidade da noção de mônada versus a particularidade da noção de período: por fim, Bronckart (2017, p. 66) informa o leitor do último problema da classificação de Berrendoner e Béguelin: "a noção de período não nos parece operacional, sobretudo porque em razão de critérios prosódicos de sua demarcação, só é pertinente para alguns gêneros do texto, e inadequada para os textos primeiramente produzidos em modalidade escrita.".

Em linhas gerais, podemos dizer que a crítica de Bronckart (2017) incide sobre o que ele mesmo chama de "extrapolação epistemológica", isto é, a criação e a manutenção de critérios heterogêneos para classificação de "tipos" de frases ou unidades. Para o autor, por fim, no último parágrafo do texto, fica evidente que a única entidade "segura" da língua é a mônada, quer dizer, a frase sintática.

No item seguinte, traremos um breve apanhado das ideias e da matriz epistemológica de Berrendoner e Béguelin (1989) antes de nos posicionar sobre o debate de ideias gerado em torno da questão da frase. A querela sobre esse tema é antiga, sendo inclusive presente na gramática, logo, não podemos assumir ou rebater qualquer classificação sem um levantamento inicial. 


\section{Berrendoner e Béguelin (1989), uma retomada}

No texto "Décalages: les niveaux de l'analyse linguistique", chama-nos atenção que os autores não têm como objetivo principal defender uma classificação. De fato, eles estão mais preocupados em desvelar uma problemática classificatória do que chamam fenômenos demarcativos, nos seguintes termos: "até aqui com efeito as observações feitas sobre cada nível (letra ou grafema, "signo" gráfico ou palavra, frase, parágrafo...) não foram muito integrados ou confrontados" (BERRENDONER; BÉGUELIN, 1989, p. 99, tradução nossa) $)^{3}$.

Além disso, os autores deixam bem claro que estão preocupados em estudar os fenômenos demarcativos no que chamam de língua escrita em oposição à língua oral. Vejamos: "A articulação 'natural' assim assumida pelas demarcações do escrito condicionam profundamente o conhecimento espontâneo pelos sujeitos falantes; ela preenche uma função derivada de natureza quase epistemológica" (BERRENDONER; BÉGUELIN, 1989, p. 99, tradução nossa, grifos nossos)4 ${ }^{4}$. Assim, para Berrendoner e Béguelin (1989), há uma cisão de matriz epistemológica entre língua escrita e língua falada e não entre língua como sistema e língua como semântica, duplo domínio linguístico, como lera Bronckart (2017) ao atrelar o pensamento dos referidos autores à distinção de domínios proposta por Benveniste.

Em seguida, Berrendoner e Béguelin (1989, p. 104, tradução nossa) ${ }^{5}$ tratam de demonstrar que a demarcação (signo, palavra, frase) é de caráter universal, pertencendo às mais diversas línguas: “De fato, a maior parte dos tipos de escritura separa as palavras, por um branco ou interpalavra como em hitita, por um travessão ou interpontuação como em miceniano.". Mais adiante, os autores consideram mesmo que entre unidades de fala e unidades de escrita há defasagens, em que "as demarcações gráficas são os traços de uma estruturação prática, imediata, espontânea, 'natural', da língua, operada por seus utilizadores" (BERRENDONER; BÉGUELIN, 1989, p. 106, tradução nossa) ${ }^{6}$. Na seção intitulada Osmoses, chegam a dizer que os modelos formais e os modelos práticos

\footnotetext{
3 No original: "Jusqu'ici en effet les observations faites sur chaque niveau du système (lettre ou graphème, « signe » graphique ou mot, phrase, paragraphe,...) n'ont guère été confrontées ni intégrées".

4 No original: "L'articulation « naturelle » ainsi assumée par les démarcations de l'écrit conditionne profondément la connaissance spontanée des structures linguistiques par les sujets parlants: elle remplit une fonction dérivée de nature quase épistémologique.".

5 No original: "De fait, la plupart des types d'écriture séparent les mots, par un blanc ou intermot comme en hittite, par un tiret ou une interponction comme en mycénien.".

6 No original: "les démarcations graphiques sont la trace d'une structuration pratique, immédiate, spontanée, «naturelle», de la langue, opérée par ses utilisateurs.".
} 
- Proposição, frase, período: uma questão epistemológica ou hermenêutica?

disputam o mesmo objeto, existindo entre eles uma certa tensão dialética, "cada um deles tende a reduzir o outro, por absorção de certos de seus esquemas" (BERRENDONER; BÉGUELIN, 1989, p. 111, tradução nossa) ${ }^{7}$.

Um trecho relevante é o que os autores dizem que a extrapolação epistemológica dos modelos práticos à gramática e dos modelos formais à língua beneficia a descrição da língua escrita em detrimento da descrição da língua falada. No entanto, "ela conduz a uma aporia. Ela não é, com efeito, legítima a não ser na condição de supor a articulação de enunciados, notadamente orais, e sua segmentação ortográfica, um isomorfismo exato" (BERRENDONER; BÉGUELIN, 1989, p. 112, tradução nossa) ${ }^{8}$. Aqui vemos que a "extrapolação epistemológica" que Bronckart acusa nos autores é percebida por eles mais como uma "necessidade contingencial" do que uma solução definitiva. Observamos, assim, a elaboração de uma crítica muito dura ao trabalho dos linguistas.

Ainda sobre a classificação mônada x período, constatamos, ao ler Berrendoner e Béguelin, que os autores estão mais preocupados em definir a mônada como "nível único entre duas ordens da combinatória. Pois ela é, ao mesmo tempo, a unidade máxima da sintaxe de recção e a unidade mínima da sintaxe de pressuposição" (BERRENDONER; BÉGUELIN, 1989, p. 114, tradução nossa) ${ }^{9}$, do que em evidenciar a existência de duas ou mais "ordens" de língua, tal como em Benveniste. Para os autores, o traço definidor da cláusula ${ }^{10}$ é a de estabelecer um "estado informacional", constituir um elemento mínimo da memória discursiva", a qual terá, no período, a sua plena expressão. Na seção final do artigo, os autores preocupam-se quase exclusivamente em demonstrar a pertinência dessa classificação para a língua escrita. Não constatamos em seu texto nenhuma reflexão mais detida sobre a noção de período.

Na seção Conclusion, os autores deixam registrada a seguinte ressalva sobre a distinção existente entre categorização formal e categorização prática:

7 No original: "chacun des deux tend à réduire l'autre, par absorption de certains de ses schémas.".

8 No original: "elle mène à une aporie. Elle n'est en effet légitime qu'à condition de supposer entre l'articulation des énoncés, notamment oraux, et leur segmentation orthographique, un isomorphisme exact.".

9 No original: "niveau seuil entre deux ordres de la combinatoire. Car elle est à la fois l'unité maximale de la syntaxe de rection, et l'unité minimale de la syntaxe de présupposition".

10 Ainda, aqui, analisando a argumentação de Berrendoner e Béguelin, preferimos a tradução de clause para cláusula do que para mônada, para seguir a denominação em alguns estudos como Halliday (1985), Perini (1996) e Decat (1999).

11 Memória discursiva é definida por Berrendoner e Béguelin (1989, p. 113) da seguinte forma: "le stock structuré d'informations que gèrent coopérativement les interlocuteurs." Esse termo é utilizado oito (8) vezes no texto e todas se referem ao autor Reichler-Béguelin (1988), autor da área da linguística textual, a mesma de Berrendoner e Béguelin. Nesse caso, não cabe discutir essa noção em outra perspectiva teórica. 
[...] seria ilusório considerar que o discurso admite sempre uma segmentação e uma única. Tudo indica que, ao contrário, a delimitação de seus constituintes é frequentemente sujeita a variações e metanálises. É então necessário, para modelizar as unidades, recorrer a uma gramática polilectal: aqui, como em outro lugar, a variação não é um acidente marginal, mas um modo de funcionamento ordinário do sistema. (BERRENDONER; BÉGUELIN, 1989, p. 124, tradução nossa) $)^{12}$.

Na seção a seguir, apresentaremos a "solução" dada por Adam para o problema das classificações das unidades da língua. Acreditamos que ficou claro em nossa exposição que a crítica de Bronckart (2017) a Berrendoner e Béguelin (1989) foi um tanto quanto injusta: assim como o autor, os linguistas estão atentos à forte heterogeneidade que circunda as classificações em torno da suposta unidade "frase".

\section{Engrossando o caldo da discussão: Adam (2019)}

Diferentemente de Berrendoner e Béguelin, que dividem as classificações em torno da "frase" em modelização formal (sintagma, cláusula, período) e classificação prática (palavra, frase, parágrafo), Adam (2019) procura outras respostas. O mais interessante em sua argumentação é que ele, além de citar Berrendoner e Béguelin (1989) e Bronckart (ainda que não exatamente o mesmo texto a que nos referimos), parece responder "implicitamente" os quatros problemas epistemológicos levantados por Bronckart (2017). Retomemos: 1) as várias acepções da noção de frase; 2) a definição da metodologia de análise, ascendente ou descendente; 3) a matriz epistemológica, a concepção de língua; 4) a universalidade da noção de mônada versus a particularidade da noção de período.

Ao primeiro problema, Adam (2019) inicia a Introdução do livro trazendo Saussure em seus Escritos: "Não há nenhum rudimento de fato linguístico fora do ponto de vista definido que preside às distinções" (2000, p. 200 apud ADAM, 2019, p. 17). Com isso, o autor inicia a problemática das heterogeneidades do estudo do texto, estabelecendo as bases das diferenças que lhe são fundamentais entre as categorias de (proto)tipos de sequências, gêneros do discurso e gêneros de texto, que virão a constituir a sua proposta de análise textual dos discursos (ADAM, 2019, p. 34). Adam (2019) elenca a existência de quatro (4) tipologias, a saber, tipologias de âmbito textual e discursivo, tipologias pragmáticas

\footnotetext{
12 No original: “il serait illusoire de considérer que le discours admet toujours une segmentation et une seule. Tout indique au contraire que la délimitation de ses constituants est souvent sujette à variations et métanalyses. Il est donc nécessaire, pour en modéliser les unités, de recourir à une grammaire polylectale: ici comme ailleurs, la variation n'est pas un accident marginal, mais un mode de fonctionnement ordinaire du système.".
} 
- | Proposição, frase, período: uma questão epistemológica ou hermenêutica?

centradas sobre os atos de discurso, tipologias enunciativas e tipologias semânticas, apenas para afirmar que adotará uma abordagem unificada das sequências textuais. De certa forma, Adam (2019) parece se aproximar de uma solução "unificadora", tal como Bronckart (2017) reivindica.

Para o segundo problema, Adam (2019) manifesta-se da seguinte forma, fazendo uma referência ao esquema de análise textual de discursos que ele propõe:

A uma dupla crítica de ancoragem epistemológica, em uma problemática "lógico-gramatical" (Rastier, 2001) e de modelagem composicional 'ascendente' (Bronckart, 1996), responderei que o quadro teórico resumido pelo Esquema 1 é claramente "descendente" e que enfatiza o papel maior dos gêneros e da interação sócio-discursiva. Ele só é parcialmente "ascendente" nos níveis N4 e N5 da parte inferior do esquema, que não permitem chegar ao nível textual. Os procedimentos de gestão da informação textual - na produção e na interpretação - alternam os momentos "descendentes" (do global para o local) e ascendente (do local para o global, em etapas de estruturação) de acordo com procedimentos que nada têm de linearidade lógico-gramatical. (ADAM, 2019, p. 36, grifos nossos).

Os níveis 4 e 5 que Adam (2019) menciona são, respectivamente, a textura (proposições enunciadas e períodos) e estrutura sequencial (sequências e planos de texto). Ou seja, o autor acredita que o nível das proposições ou períodos deve receber uma abordagem ascendente, concordando, portanto, mais como Berrendoner e Béguelin (1989) e menos com Bronckart (2017). Adam (2019) compreende que a metodologia linguística de análise dos níveis linguísticos é tanto ascendente quanto descendente, corroborando assim a dupla natureza da língua, tal como preconizara Benveniste (1989). O terceiro problema, diretamente vinculado ao segundo, é respondido "de lambuja": Adam (2019), ao propor mais de uma tipologia de análise textual dos discursos e, ao considerar uma dupla entrada para a análise (ascendente e descendente), concorda com a cisão entre linguagem e língua bem como entre língua como sistema semiótico e língua como sistema semântico, que está na base do pensamento saussuriano e benvenisteano de língua.

Sobre o quarto problema, Adam (2019) tematiza diretamente o problema do parágrafo e do período, situado no nível de análise que chama mesotextual de estruturação e atribuindo tal estudo à linguística textual. Acrescenta ainda: "É necessário considerar três grandes tipos principais de agrupamentos de proposições elementares: em períodos e em parágrafos, unidades textuais fragilmente tipificadas, e em sequências, unidades mais 
complexas e tipificadas." (ADAM, 2019, p. 45). O período e o parágrafos são "fragilmente tipificados", pois não é possível estabelecer um critério externo (ou descendente, ou de gênero de texto e discurso) para caracterizá-lo. Adam (2019) cita o exemplo de um parágrafo de um conto de Borges em que a estrutura sequencial não está completa, pois o narrador pretende dar mais atenção narrativa a outro ponto da história. Assim, sequência e parágrafo (com períodos) não são unidades com relação de "osmose", para retomar a metáfora de Berrendoner e Béguelin (1989). Ainda assim, Adam (2019, p. 49) traz a proposta de Longacre (1980) de parágrafos tipificados, a saber, "temáticos dão conta de objetos de discurso distintos; os enunciativos enfatizam mudança de atribuição da fala, um novo ato de discurso ou um comentário; os genéricos comportam uma caracterização tipológica, podendo ser narrativos, argumentativos ou descritivos.". Faz a ressalva de que são parágrafos tipificados, mas que esta regra não se aplica a todos os casos.

De certa forma, Adam (2019) corrobora a oposição universal x particular na estruturação geral das línguas, discordando implicitamente da pertinência do problema posto por Bronckart (2017). Outro ponto a ser destacado é que tanto Bronckart (2017) quanto Adam (2019) dizem-se valor dos pressupostos teóricos de Bakhtin para a análise dos gêneros, mas têm interpretações diferentes para a sua caracterização. Vejamos o que diz Adam (2019, p. 24-25):

Sua reflexão [de Bakhtin] tinha algo de interessante, a meu ver, porque ele estendia os limites da competência linguística dos sujeitos para além da frase, em direção aos "tipos relativamente estáveis de enunciados e àquilo que ele chama em outro trabalho de "sintaxe das grandes massas verbais" [...]. Se falam de "tipos relativamente estáveis de enunciados, seus escritos insistem na extrema mobilidade e na diversidade das réplicas breves, do diálogo cotidiano, da narrativa familiar e da carta.

Constatamos que, embora Adam (2019) concorde com Bronckart (2017) sobre a necessidade de uma abordagem unificada dos problemas da sintaxe do texto, o desenvolvimento de sua abordagem textual deixa entrever que não é possível tipificar plenamente o nível mesotextual de estruturação da língua.

\section{Proposição, frase, período: questão epistemológica ou hermenêutica?}

O objetivo deste trabalho é o de realizar um cotejo sobre diferentes perspectivas em torno das "unidades da língua", em especial, aquelas que estão na fronteira entre o signo e a frase, ou entre as "duas maneiras de ser língua" (BENVENISTE, 1989). Percebemos 
- | Proposição, frase, período: uma questão epistemológica ou hermenêutica?

neste trabalho que os autores valorizam de forma diferente o "ponto de vista do locutor e não do conhecedor" (NORMAND, 2009, p. 45) sobre a língua bem como tratam de forma diferente a matriz epistemológica, mesmo citando grandes linguistas como Saussure, Bakhtin e Benveniste. Reforcemos: tanto Bronckart (2017) quanto Adam (2019) citam Saussure e Bakhtin, mas a forma de compreensão é bastante diferente. Isto nos leva à seguinte questão: seriam as diferenças entre Bronckart e Berrendoner e Béguelin uma questão de "extrapolação epistemológica"?

Necessário definir inicialmente o que estamos chamando de "epistemologia". Em Lalande (1999), encontramos: "é o estudo crítico dos princípios, das hipóteses e dos resultados das diversas ciências, com a finalidade de determinar seus fundamentos lógicos, seu valor e sua importância objetiva.". De uma certa forma, a querela entre Bronckart (2017) e Berrendoner e Béguelin (1997), com a evidente tomada de partido de Adam (2019) por esta última perspectiva, como demonstramos, não tem um fundo expressamente epistemológico, já que os dois lados da contenda tomam princípios e hipóteses de matrizes epistemológicas diferentes, a saber, as respectivas concepções de língua e linguagem de Bakhtin e Benveniste. Além disso, observamos que há diferentes interpretações do legado bakhtiniano sobre a noção de "gênero discursivo": Bronckart (2017) enfatiza a busca das regularidades e das universalidades; Adam (2019) evidencia o advérbio "relativamente" no famoso sintagma bakhtiniano "gênero como relativamente regular". Enfim, detectamos aí um dilema epistemológico.

A nosso ver, então, essa questão só será resolvida por uma incursão pela hermenêutica. Utilizaremos como referência a leitura de uma das maiores especialistas de Benveniste, Irène Fenoglio (2019), sobre o estatuto da frase na Teoria Enunciativa do autor. A nosso ver, a autora faz uma leitura hermenêutica de Benveniste, pois busca respostas nos detalhes textuais, isto é, nas citações, enfim, na argumentação e ponderação sobre as ideias linguísticas do autor. Dito isto, colocamos a seguinte questão: seria a "frase" um divisor de ordens linguísticas, como na perspectiva de Berrendoner e Béguelin (1989), ou "mais" um elemento de regularidade linguística como qualquer outro, como na perspectiva de Bronckart (2017)? No item a seguir, apresentaremos a leitura de Fenoglio (2019).

\section{Benveniste: pomo da discórdia ou voto de Minerva?}

Fenoglio (2019) inicia o texto problematizando que, com a tripartição proposição, enunciado e frase, estamos no centro da "cabeça de Medusa" da teorização da linguagem. Afirma ainda que a noção de frase em Benveniste é ao mesmo tempo rigorosa e infinita em sua busca e compreensão (FENOGLIO, 2019, p. 184). Acrescenta que Benveniste não 
toma o termo proposição e sim frase como unidade entre o signo e o enunciado. Cita Tullio de Mauro, a propósito de Saussure, fazendo valer as mesmas considerações para a linguística de Benveniste:

Os traços mais típicos da personalidade intelectual [de Saussure] e sua obra: a refutação de toda mistificação, de toda falsa clareza; a parcimônia galileana na introdução de neologismos técnicos (ele prefere a via da definição estipulativa que redetermina e disciplina tecnicamente o uso de palavras correntes). (FENOGLIO, 2019, p. 185, tradução nossa) ${ }^{13}$.

Fenoglio (2019) propõe quatro perspectivas para a noção de frase em Benveniste, a saber, a frase como focus epistemológico da relação forma-sentido; a frase como "unidade do discurso"; enunciação: teoria da produção de frases; uma epistemologia do imprevisível. De cada um desses itens, procuraremos reter as ideias essenciais para entender a questão das unidades da língua.

No item A frase como focus epistemológico da relação forma-sentido, ela afirma que: "Se não podemos afirmar que Benveniste 'inventa' o discurso, podemos afirmar, ao contrário, que ele institui o 'aparelho formal' do discurso e contrariamente à afirmação do Curso de Linguística Geral, mostra que na instância de discurso há também o coletivo" (FENOGLIO, 2019, p. 188). Aqui observamos que, para Benveniste, a frase não simplesmente é um construto ou unidade linguística que cria "outra" realidade linguística: a frase é o locus onde estão contidos traços ou determinantes que revelam a face coletiva da língua (signos) mas que estão em função de um sentido, de uma mensagem particular. Nesse sentido, nos parece que nem Berrendoner e Béguelin (1989) e muito menos Bronckart (2017) compreenderam plenamente a questão das unidades da língua. Ambos, ao enfatizarem o aspecto metodológico de uma suposta abordagem "ascendente" ou "descendente" estão levando muito a sério a metáfora da língua como uma arquitetura textual, isto é, considerando a língua como algo "estático" que pode ser "fatiado". Aliás, Bronckart utiliza mesmo o termo arquitetura textual em outros textos, tais como o clássico de 1997.

No item A frase como "unidade do discurso", Fenoglio (2019) conceitua a frase como tendo uma função proposicional fundamental. Retoma o trabalho de Ono (2007),

13 No original: "Les traits les plus typiques de la personnalité intellectuelle [de Saussure] et de son oeuvre: le refus de toute mystification, de toute fausse clarté; la parcimonie galiléenne dans l'introduction de néologismes techniques (il leur prefere la voie de la définition stipulative qui redetermine et discipline techniquement l'usage des mots courants)". 
- | Proposição, frase, período: uma questão epistemológica ou hermenêutica?

que observa argutamente que, em Benveniste, a noção de predicação é complexa, constituindo-se um ato semântico. Nas próprias palavras do linguista: "O predicado é uma propriedade fundamental da frase, não é uma unidade da frase. Não há muitas variedades de predicação. A frase não é uma classe formal que teria por unidade 'frasemas' delimitados e opostos entre si." (BENVENISTE, Os níveis de analise linguística, p. 129, apud FENOGLIO, 2019, p. 195, tradução nossa) ${ }^{14}$. Novamente, observamos aqui que a noção de frase não se soma ao lado da noção de proposição: a frase, como ato enunciativo, contém a predicação, sendo ela dita função predicativa proposicional. A proposição está "escondida" na frase.

No item Enunciação: teoria da produção de frases, Fenoglio mostra que Benveniste substitui o termo "frase" por "enunciação" no seu derradeiro texto, "O aparelho formal da enunciação". "O discurso é a instância (presença de um "eu-tu", tempo + espaço) da enunciação" (FENOGLIO, 2019, p. 199, tradução nossa) ${ }^{15}$. Observamos aí que a dupla proposição e frase é substituída, ou melhor alargada, pela dupla discurso e enunciação. Assim, o discurso é a dimensão analítica ou "analisável" da enunciação, mas, de qualquer forma, contida na enunciação.

Por fim, na seção Uma epistemologia do imprevisível, Fenoglio mostra que Benveniste ousa unir a previsibilidade do sistema linguístico com a imprevisibilidade do ato de enunciação, a liberdade do falante. "Podemos dizer que Benveniste funda uma epistemologia do imprevisível linguageiro, imprevisível quanto ao enunciado mas não quanto ao sentido que advém da comunicação e da qual deriva a essência da linguagem." (FENOGLIO, 2019, p. 202, tradução nossa) ${ }^{16}$. A brilhante conclusão desta importante hermeneuta de Benveniste nos mostra que o castelo de cartas da "arquitetura textual" tanto de Berrendoner e Béguelin quanto de Bronckart cai por terra. Fica da discussão, a nosso ver, a perplexidade e a argúcia de Adam (2019) ao trazer o exemplo da noção de parágrafo em conto do poeta Jorge Luiz Borges, contraponto à sua própria teoria da estruturação do nível mesotextual da língua.

Abaixo, apresentamos a análise de Adam (2019, p. 47) de uma oração periódica extraída de uma fábula de Borges ( $O$ cativo), como prova de que as distinções no nível

14 No original: “Le prédicat est une propriété fondamentale de la frase, ce n'est pas une unité de frase. II n’y a pas plusieurs variétés de prédication. [..] La frase n'est pas une classe formelle qui aurait pour unités des 'phrasèmes' délimités et opposables entre eux.".

15 No original: "Le discours est l'instance (présence d'un 'je-tu', temps + espace) de l'énonciation.".

16 No original: “On peut dire que Benveniste fonde une épistemologie de l'imprévisible langagier, imprévisible quant à l'énoncé lui-même mais quant au sens qui advient en communication et dont il dit que là s'y trouve l'essence même du langage.". 
mesotextual não podem ser resolvidas com uma simples escolha metodológica de "análise descendente" ou "ascendente". Vejamos a análise na íntegra:

"[a] Esta lembrança talvez tenha sido acompanhada por outras [b] mas o Índio não podia viver entre quatro paredes, [c] e um dia partiu para reencontrar seu deserto.

Essa frase periódica não forma uma sequência textual claramente tipificada. É um período ternário, cujos membros [b] e [c] são introduzidos por um conector de valor tipicamente forte: "mas" dispara [b] em um sentido argumentativo, enquanto "e um dia" [c] conduz o fato para um sentido narrativo. Se partirmos de MAS, a proposição [a] é interpretável como um primeiro argumento [Arg. P] para uma conclusão C implícita, que vai no mesmo sentido contextual do final do parágrafo anterior: o filho, capturado pelos índios e encontrado por seus pais, recupera a memória e permanece com eles. Mas o cativeiro se reverte e, reencontrando sua identidade de índio, a proposição [b] se transforma em um novo argumento e a proposição [c] assume um valor de conclusão tirada de [b-arg q]: Concl. Não C. Em torno de MAS, dois mundos se opõem: um do reencontro do filho perdido com seus pais; o outro, o da separação inelutável; o primeiro, de restauração da ordem inicial; o outro, de destruição dessa ordem e da impossibilidade de retorno. [...] O fato de que esse período forme uma sequência narrativa incompleta - depois de um parágrafo que era uma estrutura narrativa completa e desenvolvida, inscrita, além disso, no gênero narrativo da crônica - salienta que o narrador não está suficientemente interessado nos novos acontecimentos para contar o resto da história e que o objeto principal desse texto, sua argumentação, está em outro lugar. (ADAM, 2019, p. 48).

Da análise acima, fica a constatação de que a "frase periódica" - conforme a própria denominação de Adam, pode conter um (1) período em uma leitura; ou dois (2) períodos em uma segunda leitura. Assim, as diferentes leituras permitem a coexistência de duas sequências entrecruzadas, a argumentativa e a narrativa. Se assumirmos a coexistência de duas leituras, o raciocínio de Benveniste está certo, ao propor que há dois conceitos de "frase", um da ordem da língua e outro da ordem do discurso. Independentemente de Adam (2019) filiar-se mais explicitamente a Benveniste ou a Bakhtin, sua análise ressalta que o texto literário tem uma característica incontornável: a "polissemia", fato semântico, tem repercussão na estruturação mesotextual da língua. 
Consideramos assim que Benveniste "absolve" a língua da prisão classificatória, sendo o voto de Minerva que inocenta o falante em sua enunciação e a sempre "falha" análise discursiva que outrem possa lhe impingir. Benveniste, a nosso ver, coloca o linguista num lugar muito parecido com o de Saussure, como bem lembrou Fenoglio: o de um juiz suspeito e em permanente suspensão de garantias.

\section{Proposição, frase, período: questão epistemológica ou hermenêutica? Resposta à questão}

Como procuramos demonstrar no artigo, a distinção entre proposição, frase e período não pode ser resolvida simplesmente ao "tomar partido" na querela entre Bronckart e Benveniste. Trata-se, de fato, de uma questão hermenêutica, como demonstrou, principalmente, Fenoglio (2019) e também constatou Adam (2019) em análise de texto literário, o qual, por natureza, não se enquadra em classificações gramaticais ou linguísticas. A nosso ver, como bem demonstra Adam (2019), e também admite o próprio Bronckart (2017) na conclusão de seu artigo, há textos que permitem uma categorização clara e principalmente "favorecedora" da leitura e há textos que apresentam uma categorização ambígua, dupla ou mesmo vaga e, portanto, a análise deve desdobrar diferentes categorizações.

Entender o nível mesotextual da língua é, a nosso ver, uma tarefa que ainda deve ser mais investigada. É propriamente nesse nível que a língua se converte em discurso, que há semantização da língua (BENVENISTE, 1995, p. 83, grifos nossos). Essa conversão - termo carregado de mistérios - não é, a nosso ver, uma "extrapolação epistemológica" como interpreta Bronckart (2017) na teorização elaborada por Benveniste. É uma real questão semântica e também hermenêutica: trazer à luz os delicados e sutis processos de transformação da cláusula em mônada, da proposição em frase supõe tanto uma teoria da linguagem, uma epistemologia, quanto uma forma de interpretação da teoria assumida, uma hermenêutica. 


\section{Referências}

ADAM, J. M. Textos, tipos e protótipos. São Paulo: Contexto, 2019.

BENVENISTE, E. Os níveis de análise linguística. In: BENVENISTE, E. Problemas de Linguística Geral I. Campinas: Pontes, 1989. p. 127-140.

BENVENISTE, E. O aparelho formal da enunciação. In: BENVENISTE, E. Problemas de Linguística Geral II. Campinas: Pontes, 1995. p. 81-92.

BERRENDONER, A.; BÉGUELIN, M. J. R. Décalages: les niveaux de l'analyse linguistique. Langue française, Structurations de textes: connecteurs et démarcations graphiques, n. 81, p. 99-125, 1989.

BRONCKART, J. P. Activité langagière, textes et discours. Pour un interactionisme sociodiscursif. Lausanne: Delachaux et Niestlé, 1997.

BRONCKART, J. P.; BRONCKART, E. Mônada, frase, proposição? Desafios de um debate conceitual. In: LOUSADA, E.; BUENO, L.; GUIMARÃES, A. M. (org.). As unidades semióticas em ação: estudos linguísticos e didáticos na perspectiva do interacionismo sociodiscursivo. Campinas: Mercado de Letras, 2017. p. 51-66.

DECAT, M. B. Por uma abordagem (in)dependente de cláusulas à luz da noção de "unidade informacional". Scripta, Belo Horizonte, v. 2, n. 4, p. 23-38, 1999.

FENOGLIO, I. Proposition, phrase, énoncé chez Émile Benveniste. In: NEVEU, F. Les concepts foundateurs de philosophie du langage. ISTE editions, 2019. p. 183-204.

HALLIDAY, M. A. K. An introduction to functional grammar. 2. ed. London: Edwards Arnold Publishers Ltd., 1985.

NORMAND, C. Saussure. São Paulo: Estação Liberdade, 2009.

PERINI, M. Gramática descritiva do Português. São Paulo: Ática, 1996. 
COMO CITAR ESTE ARTIGO: SILVA, Silvana. Proposição, frase, período: uma questão epistemológica ou hermenêutica? Revista do GEL, v. 16, n. 2, p. 129-144, 2019. Disponível em: https://revistadogel.gel.org.br/

DOI: http://dx.doi.org/10.21165/gel.v16i2.2584

Submetido em: 07/09/2019 | Aceito em: 25/11/2019. 